\title{
FERDINAND DE SAUSSURE: PAI DO ESTRUTURALISMO?
}

\section{FERDINAND DE SAUSSURE: FATHER OF THE STRUCTURALISM?}

\author{
Thiago André Rodrigues Leite ${ }^{1}$ \\ Karine Rios de Oliveira ${ }^{2}$
}

\begin{abstract}
RESUMO: A partir do Curso de Linguística Geral (CLG), de Saussure (2006), objetivamos abordar aspectos da teoria desse autor que permitem questionar a classificação que recorrentemente the é feita como "pai do estruturalismo". Para isso, buscamos alguns pressupostos teóricos nessa obra, bem como em trabalhos sobre a corrente estruturalista, contrapondo todos esses pressupostos, de modo a verificar em que sentido podem se aproximar e se afastar, o que pode corroborar ou não a ideia de um Saussure estruturalista. Primeiramente, apresentamos, com base em Benveniste (2005 e 2006) e Deleuze (1974), algumas considerações sobre o estruturalismo. Esses autores nos alertam para o fato de que essa corrente se atém às formas e suas relações. Em seguida, esboçamos um modo possível de leitura do CLG, modo esse que nos permite, num terceiro momento, (re)pensar o estatuto dessa obra como estruturalista.
\end{abstract}

PALAVRAS-CHAVE: Ferdinand de Saussure; CLG; estruturalismo.

ABSTRACT: From the Course in General Linguistics (CGL), by Saussure, we aim at approaching aspects of this author's theory that allow us to question the classification that is usually done about him as "father of the structuralism". For this purpose, we bring some theoretical assumptions in this book, as well as in texts related to the structuralism, contrasting all these pillars, to verify in what sense they can seem and can move away from each other. This verification can confirm or not the idea of a structuralist Saussure. Firstly, we show, basing on Benveniste (2005 e 2006) e Deleuze (1974), some considerations about the structuralism. These authors alert us to the fact that this thought is related to the forms and their relations. After that, we outline a possible way of reading the CGL. This way allows us, in a third moment, (re)think about the statute of this book as structuralist.

KEYWORDS: Ferdinand de Saussure; CGL; structuralism.

\section{Introdução}

Dependendo do mote de leitura, é possível ler uma obra sob diferentes óticas. Pensando nisso, destacamos, por exemplo, que o Curso de Linguística Geral (doravante CLG), de Ferdinand de Saussure, permite variadas leituras, conforme os diferentes

\footnotetext{
${ }^{1}$ Doutorando do Programa de Pós-Graduação em Estudos Linguísticos (PPGEL) na Universidade Federal de Uberlândia (UFU). E-mail: thiago fucamp@hotmail.com

${ }^{2}$ Doutoranda do Programa de Pós-Graduação em Estudos Linguísticos (PPGEL) na Universidade Federal de Uberlândia (UFU). E-mail: karinerios@hotmail.com
} 
lugares teóricos nos quais se situam aqueles que se voltam para o estudo de um ou de vários aspectos dessa obra. Nesse sentido, a partir do lugar teórico em que ora nos situamos, lemos essa obra com um olhar que aponta para questões enunciativas, ou seja, questões que levam em conta a atualização da língua por um falante via atos de fala.

Nessa perspectiva, cabe dizer que tentar compreender proximidades existentes entre teóricos acerca de determinado objeto de estudo implica identificar pressupostos que sustentam determinada postura diante de tal objeto. Assim, aqueles que veem o CLG como uma obra estruturalista o fazem, possivelmente, por serem afetados pela lente teórica por meio da qual olham para essa obra. O questionamento de Deleuze (1974) de saber em que se pode reconhecer o estruturalismo, ou melhor, de que modo se podem reconhecer os estruturalistas, é bastante apropriado ao considerarmos o que Saussure (2006) afirma sobre a constituição do objeto de estudo, precedendo a ele o ponto de vista, ou seja, "é o ponto de vista que cria o objeto" (SAUSSURE, 2006, p. 15). Essa afirmação indica que o lugar do observador é primordial à constituição do objeto de estudo, uma vez que existe um dado observável, do qual se pode falar a partir de variados lugares. Definido esse lugar, constitui-se a faceta desse objeto a ser estudada.

Dessa maneira, é oportuno perguntarmo-nos, assim como perguntou Deleuze (1974), o que veem semelhantemente os chamados estruturalistas sobre o objeto de estudo "língua"? Que implicações isso tem no modo de eles lerem o CLG? E mais especificamente o questionamento central: Saussure pode ser considerado "estruturalista", ou melhor, "pai do estruturalismo"?

$\mathrm{Na}$ tentativa de discutir essas questões, apresentamos alguns fundamentos do estruturalismo, com base em dois autores que discorrem sobre essa corrente teórica, a saber, Benveniste $(2005,2006)$ e Deleuze (1974). Cumpre reforçar que, sob uma visada enunciativa, abordamos, também, alguns princípios teorizados por Saussure (2006), na obra CLG, a fim de averiguar se há pontos de convergência e divergência entre essa obra e os pressupostos teóricos do estruturalismo.

\section{Alguns aspectos da corrente estruturalista}

Benveniste (2006), referindo-se a questões do estruturalismo em linguística, pautase em dois aspectos que caracterizam essa vertente. Nesse sentido, destacamos os seguintes dizeres do autor: "primeiro, as peças do jogo e em seguida as relações entre estas peças" (BENVENISTE, 2006, p. 16). Entendemos, a partir dessa citação, que há 
elementos linguísticos constituintes do jogo (língua) e há relações entre esses elementos, interessando, portanto, aos estruturalistas, as formas e as relações entre elas. Essas relações possuem limite, considerando-se as regras do jogo, ou seja, as leis da língua.

Em relação a essa questão do limite, consideramos pertinente dizer que, conforme Benveniste (2006, p. 27), "do mesmo modo que não falamos aleatoriamente, quero dizer sem quadro, que nós não produzimos a língua fora de certos quadros, de certos esquemas que possuímos (...)" (grifos nossos). Isso nos permite entender que a criação, no sentido de deslocamentos na relação que une o significado ao significante, na constituição do signo linguístico, é sempre possível na língua, mas nós não produzimos a língua fora de certos quadros, ou seja, não é qualquer coisa que se pode fazer com ela, havendo, portanto, limite.

Referindo-se ao serbo-croata, esse autor afirma que a sequência $k r k$ forma uma sílaba, o que não acontece no francês, e, como sabemos, isso também não ocorre no português, já que seria necessário haver uma vogal. "Eis as leis de estrutura, e cada língua tem uma multidão delas. Não se termina nunca de descobri-las" (grifos nossos) (BENVENISTE, 2006, p. 17). Essa citação incita a pensar que cada língua tem suas leis de estrutura, sua singularidade, no sentido de que há as leis de estrutura, e cada língua tem uma multidão delas. Assim, não há como apreender um sistema linguístico, o princípio de ordenação, suas leis de estrutura, mas se vê o sistema funcionando, ou seja, é possível perceber-Ihe alguns traços, porém não o todo. Essas leis remetem-nos ao fato de que, segundo Deleuze (1974, p. 272), referindo-se aos estruturalistas, "só há estrutura daquilo que é linguagem", a qual comporta a língua em seu bojo. Desse modo, entendemos que a condição fundamental para que um objeto de estudo seja tratado num prisma estruturalista é ser caracterizado como estrutura e, simultaneamente, como linguagem.

Nessa perspectiva, vale dizer que Deleuze (1974) aponta alguns critérios que permitem identificar os estruturalistas por seus pressupostos, dentre eles: o simbólico; o local ou posição; o diferencial e o singular; o diferenciante, a diferenciação; o serial; e a "casa" vazia.

Deleuze (1974, p. 273), referindo-se ao primeiro critério, o simbólico, afirma que este "está no princípio de uma gênese: a estrutura se encarna nas realidades e nas imagens segundo séries determináveis". Na linguística, isso leva, conforme esse autor, à descoberta de algo que vai além das imagens e dos conceitos, a saber: o objeto estrutural, ou seja, a linguagem. 
O segundo critério diz respeito ao local, posição. Deleuze (1974, p. 276) afirma que o elemento simbólico tem um sentido "que é necessária e unicamente de 'posição", que se dá pelo que ele chama de ordem de vizinhança. Trata-se de um local estrutural a ser ocupado pelas coisas e pelos seres, diz respeito aos papéis e aos acontecimentos, nas relações estabelecidas nos locais e entre eles.

Já o terceiro critério definido por esse autor é o diferencial e o singular. Ele exemplifica esse critério relacionando, por exemplo, os fonemas $b$ e $p$, os quais só são distintivos pela relação que há entre eles. "Os fonemas não existem independentemente das relações nas quais entram e pelas quais se determinam reciprocamente" (DELEUZE, 1974, p. 279).

O quarto critério trata do diferenciante e da diferenciação. Deleuze (1974, p. 283284) aponta a coexistência, na estrutura, de "todos os elementos, as relações e valores de relações, todas as singularidades próprias ao domínio considerado" e salienta que essa coexistência não provoca espécie alguma de confusão, já que se trata de relações e elementos que coexistem e que se atualizam em diferentes momentos.

Já o quinto critério diz respeito ao que é serial, ao fato de que, segundo Deleuze (1974, p. 290-291), "a determinação de uma estrutura não se faz somente por uma escolha dos elementos simbólicos de base e das relações diferenciais em que eles entram", mas nas relações entre as séries que mantêm entre esses elementos, pelos deslocamentos simbólicos, os quais têm lugares na estrutura.

O sexto critério apontado pelo autor é o da "casa" vazia. Conforme Deleuze (1974, p. 291), "a estrutura envolve um objeto ou elemento completamente paradoxal", presente em variadas séries e nas quais ele circula, move-se. Para o autor, essa circulação dos termos simbólicos e a variação das relações diferenciais entre eles são responsáveis pelas diferentes séries, as quais existem em função de um lugar vazio pertencente ao funcionamento do simbólico. Esse vazio é, de certa forma, "ocupado" com algo que é próprio do simbólico. No entanto, pela existência de variados locais a serem ocupados por variados elementos, levando-se em conta a "casa vazia", ao contrário do que se possa imaginar, no estruturalismo, não há falta de sentido, "há demasiado sentido [...] sempre produzido em excesso pela combinação de locais na estrutura" (grifos nossos) (DELEUZE, 1974, p. 278), o que, à primeira vista, parece ir contra o posicionamento de Benveniste (2006) ao se referir a questões sobre o sentido para os estruturalistas.

Embora os estruturalistas tenham feito a ligação entre estrutura e linguagem, segundo mencionamos, podemos observar, a partir de Benveniste (2006), que algo 
parece fugir ao escopo estruturalista na linguística: a significação ${ }^{3}$. Isso indica que não importam a essa vertente teórica as diversas significações que o signo possa assumir nas mais variadas circunstâncias. Nesse sentido, cabe ressaltar que

o estruturalismo é um sistema formal. Ele não diz absolutamente nada sobre o que denominamos a significação. Nós a colocamos entre parênteses. Supomos que todo mundo compreende se dizemos: "Você tem fome", colocam tem por causa de você. Há, pois, uma combinatória com certas correlações que são codificadas, fixadas por um código de convenção [...] "Você tem razão", o verbo "ter" significa a mesma coisa do que quando digo: "Você tem frio"? Isto não interessa de forma nenhuma ao estruturalismo: Isto interessa à semiologia (grifo do autor) (BENVENISTE, 2006, p. 34).

Apesar de essa afirmação de Benveniste - sobre a não preocupação dos estruturalistas com as questões relacionadas ao sentido - parecer apontar para algo diferente daquilo que afirma Deleuze (1974) acerca do fato de haver, no estruturalismo, demasiado sentido, entendemos que ambos os autores reconhecem a existência de um número imensamente variado de sentidos que podem advir das inúmeras relações possíveis entre os elementos da estrutura, uma vez que é nessas relações que o valor de um elemento se dá, podendo afetar, por sua vez, o sentido.

Muito embora essa ideia de um não trabalho com o sentido recaia sobre o CLG, endossando a argumentação de que Saussure (2006) é estruturalista, sendo visto até mesmo como "pai do estruturalismo", e tenha desconsiderado questões sobre o sentido e, também, sobre fala e falante, essa não é a maneira como lemos essa obra, já que, mesmo esse autor tendo como foco de suas observações a língua e seu funcionamento, ele não deixa de tocar em questões concernentes à significação, fala e falante.

\section{Ferdinand de Saussure e o CLG: uma leitura possível}

Antes de entrarmos propriamente no que Saussure (2006) foca na obra CLG, julgamos oportuno circunstanciar, brevemente, o contexto de emergência dessa obra. Dessa maneira, cabe dizer que a tendência anterior a esse autor era a Gramática Comparada, em que o componente histórico era de suma importância. Paralela a isso

\footnotetext{
${ }^{3}$ Associamos, neste momento, significação a sentido, em sua modalidade semântica, assim considerada por Benveniste (2006, p. 21). Enquanto a modalidade semiótica está para a ordem da unidade dotada de sentido, "a semântica é o 'sentido' resultante do encadeamento, da apropriação pela circunstância e da adaptação dos diferentes signos entre eles. Isto é absolutamente imprevisível. É a abertura para o mundo".
} 
estava uma tendência de linguística geral em trabalhar com dados linguísticos extraídos de texto, o que, sendo frequentemente realizado com textos antigos, ainda remetia ao aspecto filológico-histórico. No entanto, a concepção de Saussure (2006) pauta-se na existência de dois modos de analisar a língua, sincrônico e diacrônico, sendo que este ocorre sempre a partir de um momento sincrônico de análise.

A novidade do enfoque saussuriano, que foi um dos que agiram mais profundamente, consistiu em tomar consciência de que a linguagem em si mesma não comporta nenhuma outra dimensão histórica, de que é sincronia e estrutura, e de que só funciona em virtude da sua natureza simbólica. Não é tanto consideração histórica que se condena aí, mas uma forma de "atomizar" a língua e de mecanizar a história (BENVENISTE, 2005, p. 5).

Saussure (2006) concebe a língua como portadora de algo que existe na coletividade, que se institui socialmente, e isso o leva a afirmar que o falante não é senhor da língua, porque existe um componente histórico, herdado, convencionado, que não the permite fazer com a língua o que quiser; é necessário atentar para o princípio de ordenação que regula determinado sistema linguístico, ou seja, algo foge ao domínio do falante. Paralelamente, esse autor aponta a existência de traços da ordem do individual, considerando as combinações individuais que cada falante faz, nos "atos de fala", os quais são momentâneos.

No CLG, a língua é o ponto central de abordagem. Esse objeto de estudo é o princípio de ordenação, o sistema linguístico, parte componente da linguagem, a qual é, segundo Saussure (2006), multiforme e heteróclita, e, logo, não passível de sistematização. Em contrapartida, a língua, como aspecto compartilhado da linguagem, é possível de generalizações invariantes, sendo, por isso, a parte sistematizável da linguagem. Desse modo, Saussure (2006, p. 27) constata a possibilidade de estudar a linguagem sob duas maneiras, tendo, pois, como objeto de estudo ou "a língua, que é social em sua essência e independente do indivíduo", objeto priorizado naquela obra, ou a fala, "a parte individual da linguagem".

Por reconhecer que há, na linguagem, algo que é individual e algo que é social, e que ela implica tanto um sistema estabelecido como uma evolução, Saussure (2006, p. 16) esclarece que a língua, nesse contexto, é o "produto social da faculdade de linguagem e um conjunto de convenções necessárias adotadas pelo corpo social para permitir o 
exercício dessa faculdade nos indivíduos", ao passo que a fala é a utilização individual, entretanto se subordina à língua, ou seja, ao princípio de ordenação e àquilo que já é adquirido por ser convencional, no sentido de que, por exemplo, "dizemos homem e cachorro porque antes de nós se disse homem e cachorro" (grifos do autor) (SAUSSURE, 2006, p. 88). Em decorrência disso, esse autor pontua que "é necessário colocar-se primeiramente no terreno da língua e tomá-la como norma de todas as outras manifestações da linguagem" (SAUSSURE, 2006, p. 16). Assim, entendemos que, para pensarmos em fala, é inevitável, antes, passarmos pelo terreno da língua, o que é pontuado por tal autor ao afirmar que a fala é necessária para o estabelecimento da língua, e esta é necessária para que aquela ocorra e produza seus efeitos.

Assim, no que diz respeito à língua e à fala, é pertinente pensar, conforme salienta Saussure, que o falante não é senhor da língua, pois esta the impõe certos limites. $O$ falante fala, mas não é de qualquer jeito. Em relação à fala, Saussure (2006, p. 21) afirma que ela "é sempre individual e dela o indivíduo é sempre senhor". Ou seja, compreendemos que, ao falar, o falante o faz individualmente, porém a partir das regras do próprio sistema linguístico.

A concepção saussuriana toma por objeto "a realidade intrínseca da língua" (BENVENISTE, 2005, p. 06), intentando descrevê-la, de um modo geral, dispensando "igual interesse a todos os tipos de línguas, escritas ou não escritas, interessando adaptar os seus métodos. Trata-se, com efeito, de saber em que consiste e como funciona uma língua" (BENVENISTE, 2005, p. 22), sem, no entanto, desprezar a fala, a qual, assim como a língua, não está dissociada do falante.

Comumente se afirma que Saussure não tenha considerado questões sobre a fala e até mesmo sobre o falante e o sentido, conforme mostram os dizeres de Silveira (2010, p. 66):

Saussure promoveu o corte que deixa de fora as questões relativas à parole, entenda-se aqui uma clara e objetiva exclusão das questões relativas à constituição do sujeito e do sentido na linguagem, higienizando assim o que compreendeu como objeto de estudo da lingüística: a língua. Em sua concepção, a língua faz a unidade da linguagem, ficando no âmbito da homogeneidade e do abstrato, sem considerar a exterioridade. $\mathbf{O}$ objeto da lingüística é uma língua onde podem ser examinadas as relações sistêmicas, abstraindo-se totalmente o uso. (grifo, em itálico, da autora) (grifos nossos em negrito) 
Entretanto, conforme abordamos mais adiante, Saussure (2006) não nos parece ter excluído questões sobre fala, falante e sentido. No entanto, alguns autores, como Silveira (2010), consideram que o papel desempenhado pelo falante, tomado pela autora como sujeito, não é reconhecido no CLG de Saussure (2006), o que constitui uma vulgata. Ainda que esse papel não tenha sido foco ali, entendemos que sua relevância foi diretamente identificada por sua participação concreta e determinante no "ato de fala" e, de modo mais sutil em outros momentos, por exemplo, quando Saussure (2006) reconhece que o falante não é senhor da língua.

Então, dizer que esse autor não trabalha a significação e nem aborda a fala e o falante, em função da primazia atribuída à língua, constituem vulgatas a respeito dos estudos saussurianos, uma vez que a significação não deixa de ser reconhecida, tendo em vista o fato de ele apontar, por exemplo, para os efeitos produzidos na interdependência entre língua e fala. Por esse autor reconhecer a língua como um meio a garantir que a fala cumpra seus destinos por conta de um falante que mobiliza a língua é um exemplo de que a significação não é excluída das constatações dele, embora esta possa não ser o que constitui, naquele momento, seus interesses.

Cabe dizer ainda que, mesmo para estudar a língua, é necessário partir de um "ato de fala" inicial, o que Saussure (2006) denomina "circuito da fala", em que os significados são associados aos significantes. Tal noção parte do princípio da existência, para Saussure (2006), de uma unidade linguística envolvida nesse processo, o signo linguístico, o qual se caracteriza pela união de dois termos, conceito (significado) e imagem acústica (significante), sendo o laço entre eles algo arbitrário e dotado de uma linearidade.

Nesse contexto, compreendemos que o fato de Saussure (2006) haver dado ênfase a determinado componente da linguagem para constituir o objeto de estudo da linguística (língua = linguagem - fala) leva ao entendimento de seus estudos como um recorte, realizado para construir seu objeto de estudo, e que, apesar de ter tido implicações dentro do próprio estruturalismo (tendo em vista o realce dado ao que há de coletivo, de social, em detrimento do individual), tal recorte não significa excluir nem a significação, nem o falante e nem a fala. Assim, perguntamo-nos: haveria alguma "conversa" entre Saussure (2006), pensando no CLG, e o estruturalismo?

\section{Saussure e o estruturalismo - que possível (não) "conversa"?}


A língua, em termos saussurianos, não é nomenclatura, no sentido de estar "colada" ao mundo; ela é a linguagem menos a fala. A língua é um sistema diferente de outros, já que possui caráter negativo, ou seja, em termos de unidade ${ }^{4}$, não se tem nada a priori, é só na relação, o que remete à ideia de que não se tem elemento antes do sistema. Nesse sentido, segundo Saussure (2006, p. 124), "a língua apresenta, pois, este caráter estranho e surpreendente de não oferecer entidades perceptíveis à primeira vista, sem que se possa duvidar, entretanto, de que existam e que é seu jogo que a constitui". Portanto, a língua é uma instituição negativa, posto que os elementos só passam a ter existência quanto são postos na relação com outros elementos do sistema. Em contrapartida, assim como outros sistemas, a língua possui caráter relacional (é um elemento na relação com outros elementos) e caráter opositivo (um elemento é o que o outro não é). Esses três fatores, quais sejam, negativo, relacional e opositivo, fundamentam a teoria do valor saussuriana, que diz respeito, minimamente, ao lugar que um elemento (peça) ocupa/pode ocupar na língua (jogo).

Nessa perspectiva, cumpre dizer que o valor linguístico resulta do agenciamento entre os fatores relacional, opositivo e negativo. Esse valor está para a ordem de um lugar que o signo assume num estado momentâneo com outros signos do sistema, o que nos leva a associar à ideia de que, de acordo com Saussure (2006, p. 90), "uma língua é radicalmente incapaz de se defender dos fatores que deslocam, de minuto a minuto, a relação entre o significado e o significante. É uma das conseqüências da arbitrariedade do signo". Essa citação permite-nos dizer que o significado não está "colado" ao significante. Por exemplo: se dizemos que "o mar é imenso" e "o mar se apaixonou", há deslocamento na relação que une o significado ao significante, já que na segunda frase o signo "mar" foi personificado, tendo ganhado outra significação.

Ainda na caracterização da língua como sistema, Saussure (2006) chama-nos a atenção para a metáfora do jogo de xadrez, a qual exemplifica a relevância de uma peça em uso, sendo movimentada pelo falante, dentro do jogo (língua). Nesse jogo, um objeto como, por exemplo, uma pedra, pode ocupar o lugar do objeto cavalo. Na língua, essa questão da substituição de um signo por outro pode ocorrer, o que deixa entrever que há lugares vazios na língua e no interior do próprio signo. Assim, entendemos que o sistema comporta lugares vazios, o que faz com que ele esteja aberto a certas possibilidades, não

\footnotetext{
${ }^{4}$ Por outro lado, "na maioria dos domínios que são objeto da Ciência, a questão das unidades sequer se esboça: são dadas de começo" (SAUSSURE, 2006, p. 123), diferindo-se, pois, do objeto língua para a linguística, sob prisma saussuriano.
} 
havendo, portanto, propriedade totalizante num elemento. Diante disso, associamos esse caráter do sistema, de certa forma, àquilo que Deleuze (1974, p. 275) chama de estrutura, ao dizer que esta "se trata de uma combinatória referente a elementos formais que, em si mesmos, não têm nem forma, nem significação, nem representação, nem conteúdo, nem realidade empírica dada, nem modelo funcional hipotético, nem inteligibilidade por detrás das aparências" (grifos nossos). Levando-se em conta essa definição de estrutura e a noção de sistema, com base em Saussure (2006), entendemos haver aí certa aproximação entre esse autor e o estruturalismo. Essa "conversa" entre eles é possível porque o sistema e a estrutura permitem que o valor de um elemento ocorra apenas na relação com outros elementos.

Ainda no que tange a sistema e estrutura, ressaltamos o que diz Deleuze (1974) sobre a oscilação entre esses termos. Referindo-se a vários autores, como, por exemplo, Lacan e Foucault, Deleuze (1974, p. 271) afirma que "uns não recusam o termo 'estruturalismo', e empregam 'estrutura', 'estrutural'. Os outros preferem o termo saussuriano 'sistema"' (grifos nossos). Dessa citação, uma questão surge para nós: Saussure (2006) emprega em sua teoria o termo sistema, o qual, conforme já abordamos, caracteriza-se por certa abertura às possibilidades, no sentido de que no "ato de fala" há sempre possibilidades outras de deslocamento entre significado e significante. Entretanto, essa abertura associada ao sistema não implica o oposto para o termo estrutura, como se tais possibilidades ali inexistissem. Portanto, parece-nos que, se pensamos em estrutura e sistema como estando para a ordem das possibilidades, poderíamos aventar certa aproximação entre esses termos.

Ademais, conforme já citado aqui, Deleuze (1974), ao elencar critérios para a identificação dos estruturalistas, menciona, por exemplo, o critério da "casa vazia", a qual é o "único lugar que não pode nem deve ser preenchido nem mesmo por um elemento simbólico" (grifos nossos) (DELEUZE, 1974, p. 299), o qual, a nosso ver, pode ser associável a signo linguístico, levando-se em conta o prisma saussuriano. Assim, relacionando a teoria do valor saussuriana a esse critério, entendemos que é preciso do vazio para que haja movimento, ou seja, ele dá possibilidade de movimento. Parece-nos que os jogos precisam da "casa vazia" para avançar e funcionar. Desse modo, esse critério, de certa maneira, tem relação com a teoria do valor saussuriana, uma vez que ambos estão relacionados ao lugar (posição), fazendo com que os elementos linguísticos se alterem dependendo das relações de vizinhança. 
Como o signo se constitui de modo relacional com os demais elementos do sistema, podemos entender que variadas são as possibilidades de combinação. Seria isso o que Benveniste (2006) afirma ao discorrer sobre as relações entre os elementos constitutivos da língua. Segundo ele, "estas relações podem ser extremamente variadas, mas elas se deixam reduzir a um certo número de condições de base" (BENVENISTE, 2006, p. 17). Ou seja, respeitando as regularidades próprias do sistema, o princípio de ordenação.

A Saussure (2006), geralmente, é atribuída a responsabilidade de haver firmado pilares para a tendência estruturalista, embora, segundo Benveniste (2005, p. 46), "ele jamais tenha empregado num sentido doutrinal o termo 'estrutura' (palavra que, aliás, por haver servido de bandeira a movimentos muito diferentes, acabou por esvaziar-se de qualquer conteúdo preciso)". Tal fato se deu porque Saussure (2006) intentou não prosseguir os estudos linguísticos da maneira como se faziam até então, ou seja, estudos que primavam pelo historicismo na busca de elementos comuns entre as línguas. Entretanto, o que há de universal entre as línguas, para Saussure (2006), é o fato de que elas são o princípio de ordenação, ou seja, cada uma delas é um sistema linguístico e, por conseguinte, tem as suas peculiaridades. Esse caráter universal das línguas pode ser visualizado na citação a seguir.

Quando os lingüistas começaram, a exemplo de Saussure, a encarar a língua em si mesma e por ela mesma, reconheceram este princípio que se tornaria o princípio fundamental da lingüística moderna: a língua forma um sistema. Isso vale para qualquer língua, qualquer que seja a cultura onde se use, em qualquer estado histórico em que a tomemos. Da base ao topo, desde os sons até as complexas formas de expressão, a língua é um arranjo sistemático de partes. Compõe-se de elementos formais articulados em combinações variáveis, segundo certos princípios de estrutura (grifos, em itálico, do autor) (grifos, em negrito, nossos) (BENVENISTE, 2005, p. 22).

Saussure (2006), apesar de apresentar, via CLG, características que o responsabilizariam pela fundação do estruturalismo, deixa entrever, nessa obra, características decorrentes daquilo que, em seu pensamento, irrompe como diferente dessa corrente teórica.

Embora tenhamos afirmado haver a ausência de preocupação com a significação nos estudos estruturalistas, dizer o mesmo a respeito da teoria saussuriana não procede, uma vez que Saussure (2006) reconhece que o signo se constitui na relação com os 
outros signos do sistema. Assim, a significação está vinculada ao valor do signo. E, se o valor, conforme já citado, se estabelece por ser negativo, por oposição e na relação entre os signos, é possível entender que a significação, para esse autor, refere-se não apenas aos elementos que constituem o signo (significado e significante), mas também entre os signos. A partir dessa constatação, consideramos que Saussure (2006) afasta-se da corrente estruturalista no que diz respeito à questão da significação, a qual, no CLG, não fica completamente restrita à relação entre significado e significante.

Se a significação é sempre possível, já que é um produto dos "atos de fala", e esses são inúmeros e, por isso, de certo modo, imprevisíveis, então ela também está para a ordem da imprevisibilidade. Ao dizermos de tais atos, pensamos no fato de haver falante fazendo associações e, nesse sentido, marcando singularidades no uso do sistema. Assim, fala, falante e significação, de acordo com nossa leitura, comparecem ao CLG, de Saussure (2006), mas, ao que nos parece, não na leitura dos estruturalistas.

Apesar dessas possíveis diferenças, configurando uma "não-conversa" entre Saussure (2006) e os estruturalistas, considerando que estes fizeram uma determinada leitura desse autor, parece-nos haver momentos em que há "conversa" entre eles, não chegando ao ponto de dizer que Saussure (2006) seja estruturalista.

Dessa forma, acreditamos que alguns fundamentos de Saussure (2006) podem ser relacionados a critérios verificados por Deleuze (1974) como comuns aos estruturalistas, isso porque esse ponto de vista teórico - dos estruturalistas - pauta-se em noções de Saussure (2006), a partir de um mote específico de leitura feito do CLG, para a constituição do que daria embasamento a esse estudo da língua. Tal enquadramento pode ser visto, por exemplo, no CLG, no "cumprimento" do critério relacionado ao simbólico (indo além da consideração do aspecto do signo linguístico), critério esse que pode ser percebido pelo fato de aquilo que Saussure (2006) situa no plano da virtualidade assumir uma estrutura: o plano das ideias amorfas e o plano dos sons, ou seja, saindo da virtualidade para a realização que se dá por intermédio do sistema linguístico, sendo a língua "um sistema de signos que exprimem idéias" (SAUSSURE, 2006, p. 24). Logo, "a linguagem representa a mais alta forma de uma faculdade que é inerente à condição humana, a faculdade de simbolizar" (grifo nosso) (BENVENISTE, 2005, p. 27), isto é, o homem é capaz de simbolizar. Assim, "empregar um símbolo é essa capacidade de reter de um objeto a sua estrutura característica e de identificá-lo em conjuntos diferentes. Isso é que é próprio do homem e que faz do homem um ser racional" (BENVENISTE, 2005, p. 27), já que é propenso a deixar para gerações futuras signos convencionados 
socialmente, sendo que essas gerações são capazes de absorver esses signos exatamente pela capacidade natural de simbolizar.

Em relação aos critérios o local ou posição, o diferencial e o singular, e o diferenciante e a diferenciação, esses critérios podem ser visualizados em Saussure (2006) no que ele diz acerca do valor linguístico de um signo. Por exemplo, ao esclarecer que o valor se dá por uma dependência paradoxal: "de um lado, o conceito nos aparece como a contraparte da imagem auditiva no interior do signo, e, de outro, este mesmo signo, isto é, a relação que une seus dois elementos, é também, e de igual modo, a contraparte dos outros signos da língua" (SAUSSURE, 2006, p. 133). Consequentemente, esse autor concebe a língua como "um sistema em que todos os termos são solidários e o valor de um resulta tão-somente da presença simultânea de outros" (SAUSSURE, 2006, p. 133); e compreende ainda que "todas as palavras que exprimem idéias vizinhas se limitam reciprocamente" (SAUSSURE, 2006, p. 134), sendo possível inclusive que alguns termos, segundo o autor, modifiquem-se pelo contato uns com os outros, estando, pois, cada termo afetado por aquilo que o cerca.

Ademais, Saussure (2006) pode ser aproximado ainda do quinto critério apontado por Deleuze (1974), o serial, já que, ao preconizar o imbricamento das relações sintagmáticas e associativas, relações essas que ocorrem via atos de fala, Saussure (2006) deixa entrever o caráter determinante que o encadeamento dos signos tem nas relações associativas e, consequentemente, na significação. As relações sintagmáticas e associativas implicam-se mutuamente ao notarmos que as combinações em termos associativos ocorrem considerando como funcionam no encadeamento com os demais elementos da série (ainda que a relação associativa constitua algo, segundo Saussure (2006), da ordem mnemônica virtual), do plano sintagmático.

Em suma, destacamos que não há valores de antemão para os signos (o que lhes define o caráter negativo, conforme já mencionamos) e que a significação dos signos é obtida por meio da oposição entre eles e pela relação que eles têm no sistema. Portanto, os critérios de Deleuze (1974) quanto ao local ou posição, ao diferencial e singular, e ao diferenciante e diferenciação, e ao serial podem ser associados às noções saussurianas de relação, de oposição e de negação na constituição dos valores linguísticos, e nas relações sintagmáticas e associativas.

A despeito dessas possíveis aproximações, compreendemos que há certa divergência entre Saussure (2006) e os estruturalistas quanto a critério da "casa vazia", a qual faz o sistema (língua) estar em ação. Entendemos haver essa divergência, já que 
Saussure (2006) leva em conta o falante, que é quem faz esse sistema funcionar, quem coloca os elementos linguísticos em jogo, quem lhes estabelece os valores e as relações. Logo, embora esse autor trate mais detidamente do funcionamento do sistema, ele não deixa de reconhecer o papel do falante nesse funcionamento, as implicações que a atuação do falante tem no sistema, apontando, a nosso ver, para o fato de tal autor não poder ser considerado como estruturalista. Compreendemos que, se Saussure (2006), a partir do CLG, pode ser alcunhado "pai do estruturalismo", é porque os estruturalistas viram nessa obra possíveis fundamentos para alicerçar seus pilares teóricos, o que não quer dizer que tais fundamentos apontem para a única possibilidade ali de leitura. Assim, entender esse autor como "pai do estruturalismo" não significa que ele seja estruturalista, mas sim que ele despertou um olhar formal para o estudo da língua sem que tenha sido propriamente um formalista, no sentido de ater-se única e exclusivamente às formas. A difusão do estruturalismo, segundo Deleuze (1974), no caso dos estudos linguísticos, deve-se muito à escola de Moscou, à escola de Praga, mas também a Saussure.

Conforme tentamos traçar com as aproximações e divergências entre o que veem os estruturalistas e o que apontam os estudos de Saussure (2006), o que é possível perceber é que não se pode afirmar categoricamente haver ou não haver "conversa" entre eles, mesmo porque é preciso pensar inclusive o termo conversa, o qual se torna questionável se for tomado como um diálogo de influências mútuas. Não que Saussure (2006) não tenha fundamentos comuns aos estruturalistas, nem que não tenha, de certo modo, os influenciado, mas não parece haver nenhum intento declarado, apesar de propor explicar ao linguista aquilo que ele faz, de estar fundando um campo, especialmente um campo caracterizado como estruturalista, tendo em vista inclusive os pontos de afastamento que pretendemos previamente elucidar.

\section{Considerações finais}

O CLG é visto muitas vezes como uma obra estruturalista que deixou demarcado como objeto de estudo somente a língua a ser observada sincronicamente, levando-se em consideração, por exemplo, parte da última frase desse livro: "A Linguística tem por único e verdadeiro objeto a língua considerada em si mesma e por si mesma” ${ }^{\text {(grifos do }}$

\footnotetext{
${ }^{5}$ Possivelmente, essa afirmação seja uma inserção dos editores do CLG (Charles Bally e Albert Sechehaye, com a colaboração de Albert Riedlinger), haja vista que essa obra não foi escrita por Saussure (2006), mas antes uma compilação que esses alunos fizeram dos cursos por ele ministrados.
} 
autor) (SAUSSURE, 2006, p. 271). Consideramos pertinente dizer que, antes dessa parte, parece ser possível entrever que não é só a língua que é considerada nessa obra, conforme aqui procuramos delinear. Nesse sentido, de acordo com Saussure (2006, p. 271), "das incursões que acabamos de fazer nos domínios limítrofes de nossa ciência, se depreende um ensinamento inteiramente negativo, mas tanto mais interessante quanto concorda com a idéia fundamental deste curso" (grifos nossos). Desse modo, compreendemos que há outras coisas incidindo no CLG, já que essa obra tem a língua como um ensinamento tanto mais interessante quanto concorda com a idéia fundamental deste curso, ou seja, se é idéia fundamental, parece, então, apontar para o fato de que Saussure (2006) não esquece nem a significação, nem o falante e nem a fala nessa obra, isto é, não olha somente para a língua.

É interessante ressaltar que a ligação que, comumente, se faz entre Saussure (2006) e o estruturalismo deve-se não ao fato de ele ser estruturalista, conforme já mencionamos, mas em decorrência de um mote de leitura de sua obra, pois Saussure (2006) estava preocupado não com o estabelecimento de pilares da perspectiva estruturalista, porém, antes, com a definição, caracterização do objeto de estudo da linguística.

Desse modo, entendemos que as elisões que Saussure (2006) deixa entrever no CLG não significam desconsiderar a existência e a relevância de questões não detalhadas. Talvez, tais elisões sejam mais propriamente um recorte para seu estudo, o que não denota nenhuma espécie de valoração, mas uma escolha metodológica. Assim, ao apontar, por exemplo, o papel do falante no sistema, esse autor abriu lugar para a possibilidade de abordagem, em outros trabalhos, de aspectos por ele já vislumbrados, como a noção de subjetividade em Benveniste e outras possibilidades desveladas em outras perspectivas. Foram as rupturas de paradigma efetuadas por Saussure (2006) que conduziram à emergência de novas possibilidades de estudo da língua.

\section{Referências}

BENVENISTE, Émile. Problemas de lingüística geral I. 5. ed. Campinas: Pontes Editores, 2005.

Problemas de lingüística geral II. 2. ed. Campinas: Pontes, 2006.

DELEUZE, Gilles. Em que se pode reconhecer o estruturalismo? In: CHÂTELET, François (org.). História da filosofia: idéias e doutrinas. v. 8. Rio de Janeiro: Zahar, 1973. 
SAUSSURE, Ferdinand de. Curso de lingüística geral. 27. ed. São Paulo: Cultrix, 2006. SILVEIRA, Verli Fátima Petri da. Algumas reflexões sobre o sujeito nos estudos da linguagem. Disponível em: <<http://www.ufsm.br/corpus/txts profes/Verli algumas reflexoes sobre sujeito.pdf $>>$ Acesso em: 05 de maio de 2012. 